\title{
Consistency of food preferences in Australian children from 2 to 5 years of age
}

Byrne, R. ${ }^{1,2}$, Mauch, C. ${ }^{3}$, Bell, L. ${ }^{3}$ and Daniels, L. ${ }^{2}$

${ }^{1}$ Institute of Health and Biomedical Innovation, Centre for Children's Health Research, Queensland University of Technology, Brisbane, Queensland, Australia

${ }^{2}$ School of Exercise and Nutrition Sciences, Queensland University of Technology, Brisbane, Queensland, Australia

${ }^{3}$ Nutrition and Dietetics, School of Medicine, Flinders University, Bedford Park, South Australia, Australia

\section{Abstract:}

While it is generally accepted that food habits established during infancy will track into later childhood, longitudinal analysis of children's food preferences is rare. This paper examines whether maternal-reported child food preferences at five years of age are the same as that reported at two years; and identifies any patterns of change from two- to five- years.

Mothers in the Australian NOURISH trial reported child food preferences at two and five years of age. A four point scale was utilised - 'like', 'neither like or dislike', 'dislike', 'never tried'. The proportion of children having the same preference at the two time points was calculated $(95 \% \mathrm{Cl})$ for 48 foods (cereals, 4; vegetables, 20; fruit, 14; meat/alternatives, 6 ; dairy, 4). For foods where $\leq 50 \%$ children had consistent preferences, the pattern of food preference change was determined.

For 40/48 foods, more than half of the children were reported to have the same preference at two years of age, and three years later, at age five. Foods for which $\leq 50 \%$ children had the same preference at both ages were high-sugar breakfast cereals, zucchini, mushrooms, eggplant, spinach, lettuce, cabbage and celery.

Findings reinforce the importance of promoting a consistent message regarding early and frequent exposure to a variety of healthy foods, particularly during the first 2 years of life, as the preferences established in these early years are likely to be maintained over time.

Keywords: Food preferences, early childhood, variety, longitudinal, fruit, vegetables 


\section{Introduction}

The importance of establishing healthy food preferences in early childhood is well recognised [1].

Diets consisting of a variety of fruit, vegetables, wholegrains and lean meats are associated with decreased morbidity and mortality throughout the life span, through the prevention of chronic diseases such as cancer, cardiovascular disease and overweight/obesity [2-3]. However infants and young children have innate preferences for sweet and salty tastes with concomitant predisposition to dislike of sour and bitter tastes [4]. This means children will generally dislike vegetables and have a preference for energy-dense, nutrient-poor foods that are ubiquitous in our 'obesogenic' environment. However, parents can potentially modify these initial flavour preferences by exposing children to a wide variety of healthy foods in early life [5-6]. Exposure to foods starts via flavour transfer in utero and while breastfeeding, and continues during introduction to solid foods [7]. It is recommended that parents introduce a wide variety of flavours and textures from around six months of age, as children younger than 24 months of age may be more receptive to new foods than older children [8-9]. This is because neophobia i.e. fear and rejection of new foods, increases rapidly during the second year of life [10], resulting in children being less likely to like and accept a new food introduced after that time.

While it is generally accepted that food habits established during infancy will track into later childhood and adolescence, longitudinal analysis of children's food preferences is rare [11]. In the United States, Skinner et al measured food preferences of 70 young children with the 196 item Food Preference Questionnaire [12]. Consistency in children's food preferences was demonstrated by the percent agreement between maternal reported food preferences at 2-3, 4 and 8 years. Preferences for fruits, meat, dairy and cereal foods were most consistent over time. While this study purported to measure the preferences of 196 foods, results were presented aggregated into 16 food categories e.g. 33 individual vegetables were collapsed into the category 'cooked vegetables'. 
A second longitudinal study identified was conducted in France and evaluated the impact of food choices at two-three years of age on food preferences in childhood through to early adolescence [13]. Participants were divided into four groups depending on their age at follow-up, 4-7 years $(n=83) ; 8-12(n=99) ; 13-16(n=68) ;$ and $17-22(n=91)$ years. Early 'preference' was determined by observing and categorising child food choices (from a selection of eight dishes) during lunch time meals at nursery school. No 'sweet' foods were offered. Early 'preference' was significantly linked to child-reported food preference at follow-up (measured by questionnaire) for 36 out of 62 foods on a specified list. These tended to be for strongly flavoured foods such as mature cheese. Vegetable preference at follow up was predicted both by early 'preference' and by age, leading the authors to conclude that generally, preference for vegetables increases during adolescence and early adulthood.

General discussion of food preferences in the literature tends to focus on the consumption of, and preference for fruits and vegetables. There is less focus on foods such as fish and wholegrains, though these foods tend to be eaten less often than recommended [8]. Improved understanding of the extent of tracking of children's preferences for a wide variety of foods - not just fruit and vegetables - is necessary to assist in the provision of evidence-based advice to parents. Therefore the aims of this paper were to examine the hypothesis that maternal-reported child food preferences at five years of age are the same as that reported at two years of age - for a comprehensive list of individual foods; and for those foods for which preference was not consistent over time, explore the pattern of change from two- to five- years.

\section{Methods}

This is a secondary analysis of longitudinal data from the Australian NOURISH randomised controlled trial [14]. Mothers aged at least 18 years with facility in English were recruited from major maternity hospitals in two Australian capital cities (Brisbane, Queensland and Adelaide, South Australia) following the birth of their first child (a healthy, term infant). Full enrolment in the study occurred 
when the child was aged 4-7 months, at which time baseline assessment and randomisation into control and intervention groups occurred $(\mathrm{N}=698)$. The intervention modules, commencing at child age 4 and 14 months, provided anticipatory guidance regarding responsive feeding strategies with the aim of reducing indicators of child obesity risk. Recruitment procedures and the intervention modules have been described in detail elsewhere [15-16]. The NOURISH study was approved by the Queensland University of Technology and Flinders University Human Research Ethics Committees and the relevant hospital ethics committees (Australasian Clinical Trials Registration ACTRN 1260800056392; QUT HREC 00171 Protocol 0700000752).

Mothers completed questionnaires at recruitment and baseline assessment to collect demographic data, such as child gender and age of introduction to solids. Questionnaires were also completed by the mother when the child was aged two and five years, recording child food preferences for a variety of foods and drinks. Questions were based on those developed by Wardle et al (2001) [17] with wording adapted to suit Australian foods. Responses were measured on a six point scale: like a lot, like a little, neither like or dislike, dislike a little, dislike a lot, never tried. Parents were instructed to indicate liking even if the child liked the food but did not usually eat or drink it.

Height and weight of mother and child were measured by research staff at child at the 2 year old assessment, and used to derive $\mathrm{BMI}\left(\mathrm{kg} / \mathrm{m}^{2}\right)$ and $\mathrm{BMI} \mathrm{z}$-score [18] respectively.

\section{Analysis}

All analyses were conducted in SPSS version 23 [19]. Both intervention and control groups were included in this analysis, as the hypothesis is whether food preferences established by 2 years of age are consistent at age 5 years, regardless of whether mothers implemented strategies between 14 months and 2 years that modified quality of food preferences overall. Furthermore, the intervention had only limited impact on food preferences [20]. 
Demographic data is presented as $\mathrm{n}(\%)$ for categorical, and mean (standard deviation) or median (interquartile range) for continuous data.

Prior to analysis, responses 'like a lot' and 'like a little' were aggregated to form a single category of 'like', and similarly responses of 'dislike a little' and 'dislike a lot' were aggregated to 'dislike' . This is because it was deemed that moving between 'like a little' and 'like a lot' represented a consistent preference over time. Thus a four point scale was utilised: 'like', 'neither like or dislike', 'dislike', 'never tried'. The proportion of children having the same reported food preference at two and five years was calculated, along with the $95 \% \mathrm{Cl}$, for 48 foods: cereals,4; vegetables, 20; fruit, 14; meat \& alternatives, 6; dairy, 4.

For those foods where $\leq 50 \%$ of the sample had consistent food preferences over time, the proportion of children in each category of food preference change was determined (supplementary table 1), and the highest three proportions reported in the results.

\section{Results}

Food preference data were available for 444 children at two years and 371 at five years, resulting in $\mathrm{N}=340$ with data at both time points. Sample characteristics are shown in table 1.

Table 1. Sample characteristics of mothers and children with food preference data available at two and five years of age $(n=340)$.

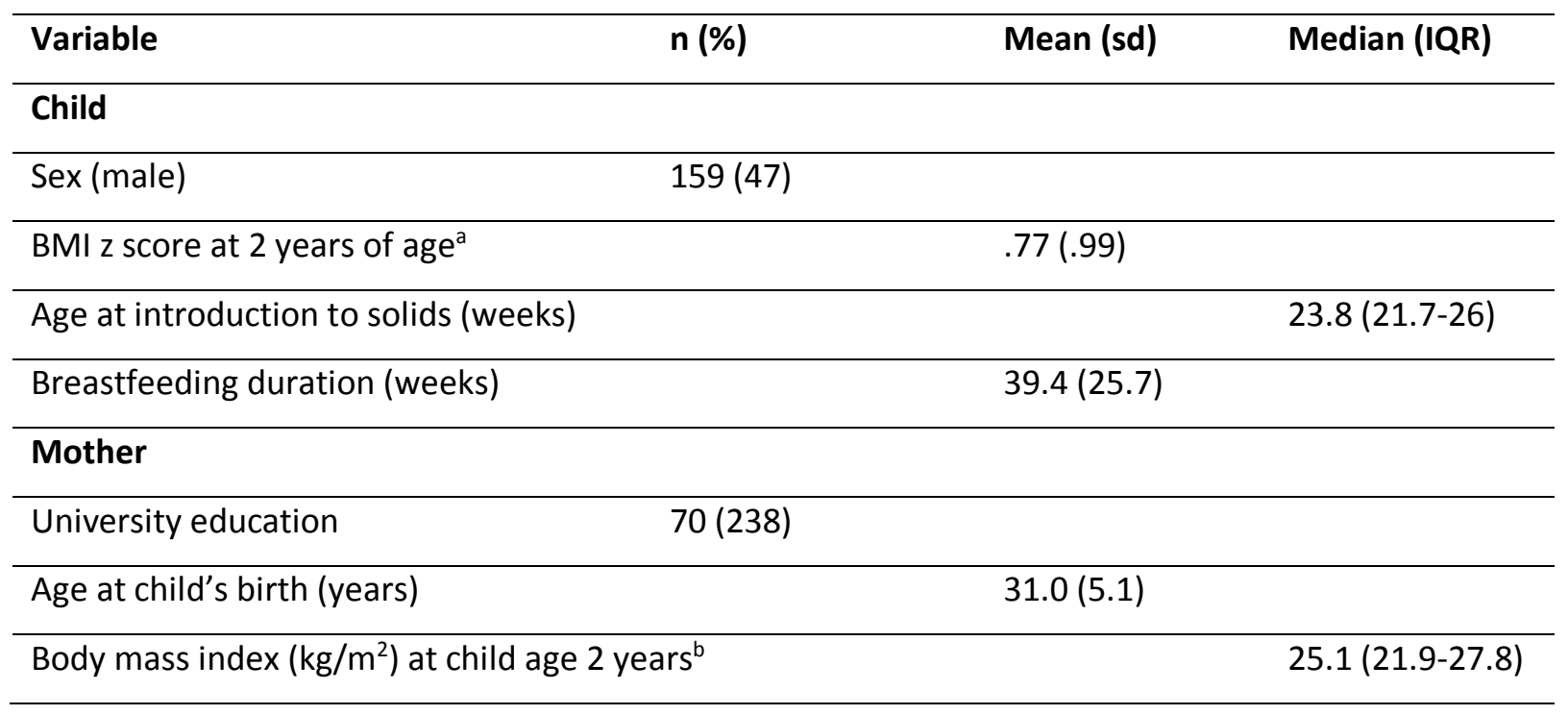


a $n=336$

${ }^{b} \mathrm{n}=240$

The proportion of children with the same reported food preference at age 2 years and 5 years, for each of the core foods is shown in table 2. While there were one or two responses missing for some foods (see table 2 footnotes), notably food preference for cauliflower at age five years was reported for only $254 / 340$ children.

Foods for which $\geq 80 \%$ children had the same preference at both ages were pasta, high fibre breakfast cereals, and rice; apples, grapes, strawberries/other berries, watermelon and bananas; carrots; poultry, red meat, eggs, and fish; cheese and flavoured yoghurt. By age five years, $48 \%$ of children had not tried paw-paw and 36\% had not tried dairy desserts. Legumes (32\%), eggplant (37\%), and brussel sprouts (51\%) were the three vegetables that had the highest proportion of 'never tried' by the sample at age five years. For a visual representation of the data, horizontal bar graphs showing the proportion of children in each preference category at two and five years for each food, are provided in the supplementary material.

Foods for which $\leq 50 \%$ of children were reported to have the same preference at both ages were high-sugar breakfast cereals, zucchini, mushrooms, eggplant, spinach, lettuce, cabbage and celery. The three main changes in food preference category for these foods are shown in table 3. 
Table 2. Prevalence of children with the same reported food preferences for specified foods at age two years and five years $(\mathrm{N}=340)$

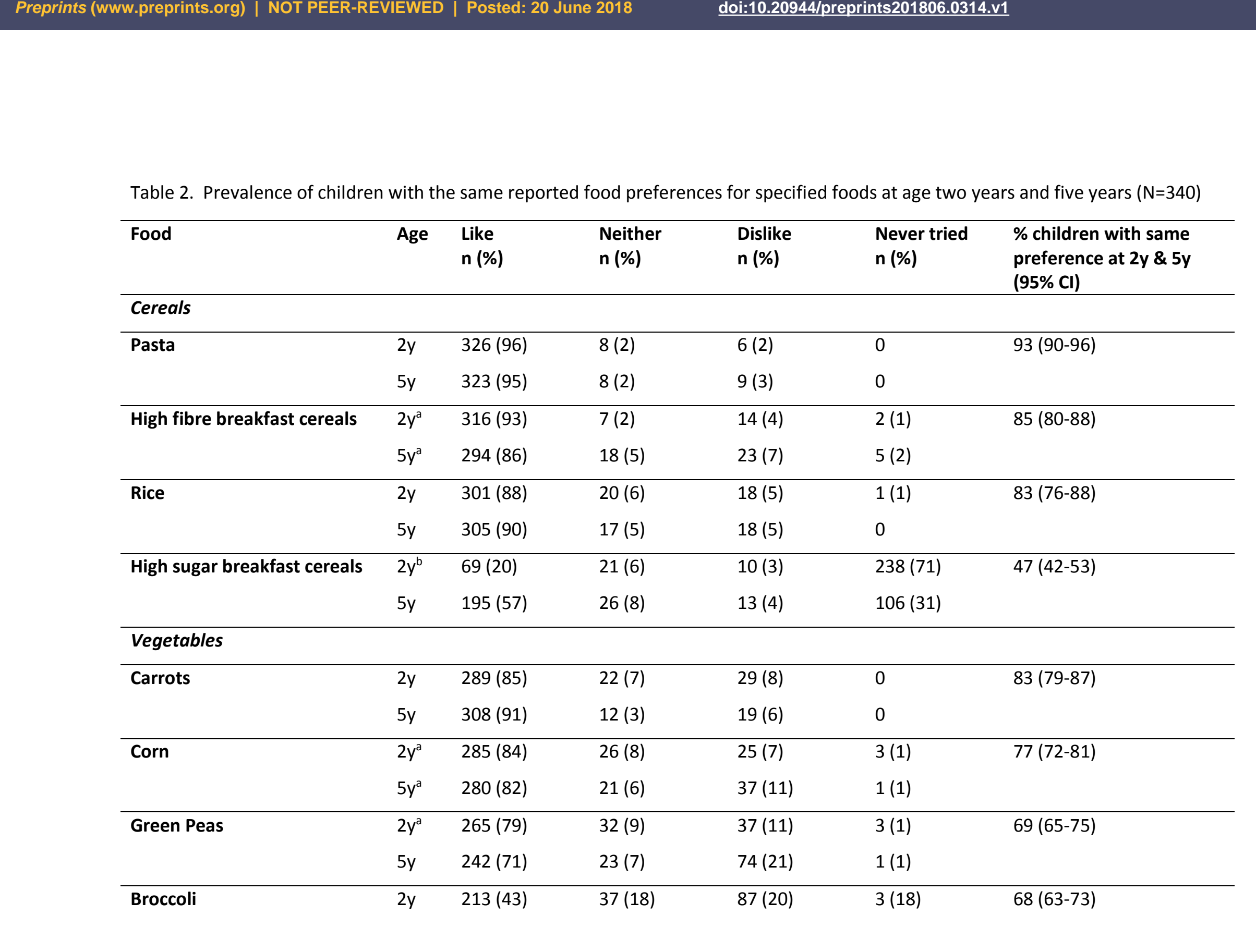

.




\begin{tabular}{|c|c|c|c|c|c|c|}
\hline \multirow[t]{2}{*}{ Sultanas } & $2 y$ & $306(90)$ & $13(4)$ & $17(5)$ & $1(1)$ & \multirow[t]{2}{*}{$78(73-82)$} \\
\hline & $5 y^{h}$ & $251(80)$ & $18(5)$ & $44(14)$ & $1(1)$ & \\
\hline \multirow[t]{2}{*}{ Pears } & $2 y$ & $291(86)$ & $21(6)$ & $23(7)$ & $5(1)$ & \multirow[t]{2}{*}{$76(71-80)$} \\
\hline & $5 y$ & $268(79)$ & $26(8)$ & $42(12)$ & $4(1)$ & \\
\hline \multirow[t]{2}{*}{ Citrus fruit } & $2 y^{a}$ & $250(74)$ & $35(10)$ & $44(13)$ & $10(3)$ & \multirow[t]{2}{*}{$73(68-77)$} \\
\hline & $5 y$ & $269(79)$ & $22(6)$ & $47(14)$ & $2(1)$ & \\
\hline \multirow[t]{2}{*}{ Peaches/nectarines } & $2 y$ & $277(82)$ & $23(6)$ & $33(10)$ & $7(2)$ & \multirow[t]{2}{*}{$72(67-77)$} \\
\hline & $5 y$ & $253(75)$ & $35(10)$ & $44(13)$ & $8(2)$ & \\
\hline \multirow[t]{2}{*}{ Rockmelon } & $2 y$ & $228(67)$ & $38(11)$ & $57(17)$ & $17(5)$ & \multirow[t]{2}{*}{$62(57-68)$} \\
\hline & $5 y$ & $205(60)$ & $29(8)$ & $89(26)$ & $17(5)$ & \\
\hline \multirow[t]{2}{*}{ Pineapple } & $2 y$ & $208(61)$ & 46 (14) & $45(13)$ & $41(12)$ & \multirow[t]{2}{*}{$59(54-65)$} \\
\hline & $5 y$ & $232(68)$ & $41(12)$ & $63(19)$ & $4(1)$ & \\
\hline \multirow[t]{2}{*}{ Kiwi fruit } & $2 y$ & $189(55)$ & $44(13)$ & $64(19)$ & $43(13)$ & \multirow[t]{2}{*}{$58(52-63)$} \\
\hline & $5 y^{g}$ & $186(61)$ & $25(8)$ & $71(23)$ & $26(8)$ & \\
\hline \multirow[t]{2}{*}{ Pawpaw } & $2 y$ & $90(27)$ & $34(10)$ & $41(12)$ & $175(51)$ & \multirow[t]{2}{*}{$58(53-64)$} \\
\hline & $5 y^{a}$ & $80(24)$ & $28(8)$ & $68(20)$ & $163(48)$ & \\
\hline \multirow[t]{2}{*}{ Plums } & $2 y$ & $177(52)$ & 47 (14) & $30(9)$ & $86(25)$ & \multirow[t]{2}{*}{$54(48-59)$} \\
\hline & $5 y$ & $182(53)$ & $58(17)$ & $53(16)$ & $47(14)$ & \\
\hline \multicolumn{7}{|l|}{ Meat/alternatives } \\
\hline \multirow[t]{2}{*}{ Poultry (home-made) } & $2 y^{a}$ & $318(94)$ & $10(3)$ & $7(2)$ & $4(1)$ & \multirow[t]{2}{*}{$90(86-93)$} \\
\hline & $5 y^{a}$ & $316(93)$ & $5(2)$ & $14(4)$ & $4(1)$ & \\
\hline Red meat (home-made) & $2 y^{b}$ & 302 (89) & $18(5)$ & $13(4)$ & $5(2)$ & $81(77-85)$ \\
\hline
\end{tabular}


Table 3. Changes in food preferences between two and five years of age, for those foods where $\leq 50 \%$ of the sample had consistent food preferences over time

\begin{tabular}{|c|c|c|}
\hline \multirow{2}{*}{$\begin{array}{l}\text { Food } \\
\text { High -sugar breakfast cereals }{ }^{a}\end{array}$} & \multicolumn{2}{|c|}{ Top three categories of preference change (\%) from $2 y$ to $5 y$} \\
\hline & Never tried to Like & 36 \\
\hline & Never tried to Neither like or dislike & 5 \\
\hline & Neither like or dislike to Like & 4 \\
\hline \multirow[t]{3}{*}{ Zucchini $^{b}$} & Like to Dislike & 18 \\
\hline & Like to Neither like or dislike & 11 \\
\hline & Neither like or dislike to Dislike & 7 \\
\hline \multirow[t]{3}{*}{ Mushrooms $^{c}$} & Neither like or dislike to Like & 16 \\
\hline & Dislike to Like & 15 \\
\hline & Like to Neither like or dislike & 8 \\
\hline \multirow[t]{3}{*}{ Eggplant $^{d}$} & Never tried to Dislike & 14 \\
\hline & Neither like or dislike to Dislike & 9 \\
\hline & Like to Dislike & 7 \\
\hline \multirow{3}{*}{ Spinach $^{\mathrm{e}}$} & Like to Dislike & 11 \\
\hline & Like to Neither like or dislike & 9 \\
\hline & Neither like or dislike to Like & 7 \\
\hline \multirow[t]{3}{*}{ Lettuce $^{b}$} & Dislike to Like & 19 \\
\hline & Neither like or dislike to Like & 13 \\
\hline & Like to Dislike & 6 \\
\hline \multirow[t]{3}{*}{ Cabbage $^{f}$} & Never tried to Dislike & 13 \\
\hline & Neither like or dislike to Dislike & 11 \\
\hline & Like to Neither like or dislike & 7 \\
\hline \multirow[t]{3}{*}{ Celery ${ }^{g}$} & Neither like or dislike to Like & 12 \\
\hline & Never tried to Dislike & 11 \\
\hline & Neither like or dislike to Dislike & 8 \\
\hline
\end{tabular}

\section{Discussion:}

This paper is one of the first to compare consistency of reported food preferences across early childhood for a wide range of foods, including cereals, meat/alternatives and dairy as well as vegetables; and the first to do so amongst Australian children. 
For 40 out of 48 foods considered, more than half of the children in the sample were reported to have the same preference at two and five years of age. That is, if they were reported to like the food at two years of age, they were also reported as liking this food when their mother was asked three years later, at age five years; and similarly for the categories, 'neither like or dislike' and 'dislike'. Foods for which a large proportion $(\geq 80 \%)$ of children had the same preference at both ages were pasta, high fibre breakfast cereals, and rice; apples, grapes, strawberries/other berries, watermelon and bananas; carrots; poultry, red meat, eggs, and fish; cheese and flavoured yoghurt. The majority of these foods are considered staple foods in the Australian diet [21], and there were very few children who had not tried these foods at two years of age - the exception being $n=12$ (4\%) children who had not tried fish and $n=18(6 \%)$ who had not had flavoured yoghurt. These foods for which preferences are consistent are also similar to Nicklaus et al who found that preferences amongst French children were most stable over time for 'starchy foods' and 'animal products' [13].

Foods for which $\leq 50 \%$ of the sample were reported to have the same preference at two and five years - i.e. the majority of children did not have a consistent preference over time - were high -sugar breakfast cereals, zucchini, mushrooms, eggplant, spinach, lettuce, cabbage and celery. Consistent with the understanding that young children have an innate preference for sweet tastes [4] the preference for high-sugar breakfast cereals overwhelmingly shifted to 'Like' at five years of age, despite $71 \%$ of children not having tried this food at two. Preference for mushrooms and celery tended to shift to 'like', while more children disliked zucchini, cabbage and eggplant over time. The sensory properties of these foods i.e. "visual (food colour), auditory (crispiness), tactile (viscosity, creaminess), or olfactory (odour) characteristics" [22] may also influence their acceptance, or otherwise, by children. Strategies recommended to parents to increase acceptance and liking, may have to become more specific, depending on a food's properties [9], i.e. is there a pattern of exposure that enhances the liking of certain tastes or textures, for example offering a food every day, versus every second day, or more specific advice on the combinations of food to be offered. 
Fourteen percent of children moved from 'never tried' to 'dislike' for eggplant and $13 \%$ for cabbage. While the category 'not tried' is not a food preference per se, it is an important consideration in the development of food preferences. Contemporary advice to parents is to limit young children's exposure to discretionary (i.e. sweet) foods for as long as possible [23] (71\% of children in this sample had 'not tried' high sugar breakfast cereals at age two) while ensuring early exposure to healthy foods in order to support the development of optimal food preferences, particularly learning to like less palatable/bitter vegetables. Legumes and brussel sprouts were 'never tried' at two years of age by $33 \%$ and $58 \%$ of the sample respectively. These foods are also those which tend to be eaten less often by Australian adults. Australian Healthy Survey data show that the cabbage, broccoli and brassica vegetable group, which includes brussel sprouts, were consumed by only $10 \%$ of adults on the day of the recall - the lowest proportion of consumers of all the vegetable groups [21]. Furthermore, only $5 \%$ of the adult population consumed legumes or legume based dishes. This raises the question of how parents can practically implement advice on introducing a wide variety of foods when they themselves do not eat a wide variety, and similarly how we encourage parents to use repeated exposure as a strategy to increase preference and intake [24]. Parents may be understandably reluctant to purchase and prepare a food that they dislike, such that the child has the opportunity to try it 7-10 times before learning to like it. In this instance, children will also not have the opportunity to see parents modelling intake of these foods. Maternal food preferences are linked with child food preferences in this cohort [25], which makes sense, given parents are the gatekeepers of food purchasing for young children, and hence to what they are exposed [26]. A limitation of this analysis is the reliance on maternal memory of child food preferences. For six foods a higher number of children were reported as having 'not tried' the food at five years of age compared with two years, e.g. eight children had not tried sweet potato at two and this increased to 10 children at age five years. However the increase ranged from only one to three participants across the six different foods. Reliance on memory may also be a strength of the study, given that it is very unlikely mothers completing the questionnaire at five years remembered what preference 
was reported for any given food three years prior, and instead are relying on children's current behaviour to determine food preferences. It is also unclear why a considerable number of mothers $(n=86)$ did not report the food preference for cauliflower at age five years. It may be because the questionnaire was paper-based and this question was the final item at the bottom of the left-hand page of the booklet, and thus was overlooked.

In addition, this sample was comprised of mothers who were older and a higher proportion had a tertiary education compared to Australian first-time mothers generally [27]. Infant feeding indicators (breastfeeding and age at introduction to solids) also aligned more closely to national guidelines in this sample, compared to most infants [28].

\section{Conclusion:}

This paper examined children's food preferences for a range of cereals, vegetables, fruit, dairy and meat/alternatives at 2 and five years of age. For 40 out of 48 of the foods examined, more than half of the children in the sample were reported to have the same preference at two years of age, and three years later, at age five. These findings reinforce the importance of promoting a strong and consistent message regarding early and frequent exposure to a variety of healthy foods, particularly during the first 2 years of life, as the preferences established in these early years are likely to be maintained over time.

Acknowledgements: We would like to thank the families participating in NOURISH, who gave so generously of their time, as well as our research teams in Brisbane and Adelaide, and NOURISH investigators, A/Prof Anthea Magarey, Professors Jan Nicholson, Diana Battistutta, Karen Thorpe, Geraldine Naughton, Ann Farrell, Geoffrey Cleghorn and Geoffrey Davidson, and A/Prof Jordana Bayer. RB would like to acknowledge the support of Lee Jones and Edward Gosden, from the Research Methods Group at the Institute of Health and Biomedical Innovation, for their support with this analysis. 
NOURISH was funded by the Australian National Health and Medical Research Council during 2008-

2010, grant 426704; and 2011-2014 grant AP1021065. Additional funding was provided by HJ Heinz, Meat \& Livestock Australia (MLA), Department of Health South Australia, Food Standards Australia New Zealand (FSANZ), and the Queensland University of Technology.

Author contributions: RB completed the statistical analysis and drafted this paper. All authors participated in data collection, conceptualisation of this analysis, and contributed to the manuscript.

LD conceptualised NOURISH, obtained funding and led the RCT.

Conflict of interest: All authors declare they have no conflict of interest.

\section{References}

1. Birch, L. L.; Doub, A. E., Learning to eat: birth to age 2 y. Am J Clin Nutr 2014, 99, 723S-728S.

2. Wang, X.; Ouyang, Y.; Liu, J.; Zhu, M.; Zhao, G.; Bao, W.; Hu, F. B., Fruit and vegetable consumption and mortality from all causes, cardiovascular disease, and cancer: systematic review and dose-response meta-analysis of prospective cohort studies. BMJ 2014, 349, g4490.

3. Dauchet, L.; Amouyel, P.; Hercberg, S.; Dallongeville, J., Fruit and vegetable consumption and risk of coronary heart disease: a meta-analysis of cohort studies. J Nutr 2006, 136, 2588-2593.

4. Mennella, J. A.; Reiter, A. R.; Daniels, L. M., Vegetable and Fruit Acceptance during Infancy: Impact of Ontogeny, Genetics, and Early Experiences. Adv Nutr 2016, 7, 211S-219S.

5. Ventura, A. K.; Worobey, J., Early influences on the development of food preferences. Curr Biol 2013, 23, R401-R408.

6. Benton, D., Role of parents in the determination of the food preferences of children and the development of obesity. Int J Obes 2004, 28 (7), 858.

7. Beckerman, J. P.; Alike, Q.; Lovin, E.; Tamez, M.; Mattei, J., The Development and Public Health Implications of Food Preferences in Children. Front Nutr 2017, 4, 66.

8. Paroche, M. M.; Caton, S. J.; Vereijken, C. M. J. L.; Weenen, H.; Houston-Price, C., How Infants and Young Children Learn About Food: A Systematic Review. Front Psych 2017, 8, 1046. 9. Nicklaus, S., Children's acceptance of new foods at weaning. Role of practices of weaning and of food sensory properties. Appetite 2011, 57, 812-815.

10. Dovey, T. M.; Staples, P. A.; Gibson, E. L.; Halford, J. C. G., Food neophobia and 'picky/fussy' eating in children: a review. Appetite 2008, 50, 181-193.

11. Nicklaus, S.; Remy, E., Early Origins of Overeating: Tracking Between Early Food Habits and Later Eating Patterns. Curr Obes Rep 2013, 2, 179-184.

12. Skinner, J. D.; Carruth, B. R.; Bounds, W.; Ziegler, P. J., Children's food preferences: a longitundinal analysis. J Am Diet Assoc 2002, 102, 1638-1647.

13. Nicklaus, S.; Boggio, V.; Chabanet, C.; Issanchou, S., A prospective study of food preferences in childhood. Food Qual Prefer 2004, 15, 805-818.

14. Daniels, L. A.; Mallan, K. M.; Nicholson, J. M.; Thorpe, K.; Nambiar, S.; Mauch, C. E.; Magarey, A., An early feeding practices intervention for obesity prevention. Pediatrics 2015, 136, e40-e49.

15. Daniels, L. A.; Wilson, J. L.; Mallan, K. M.; Mihrshahi, S.; Perry, R.; Nicholson, J. M.; Magarey, A., Recruiting and engaging new mothers in nutrition research studies: lessons from the Australian NOURISH randomised controlled trial. Int J Behav Nutr Phys Act 2012, 9, 129. 
16. Daniels, L. A., Complementary feeding in an obesogenic environment: behavioral and dietary quality outcomes and interventions. In Complementary feeding: building the foundations for a healthy life, Black, R. E.; Makrides, M.; Ong, K. K., Eds. Karger Publishers: 2017; Vol. 87, pp 167-181. 17. Wardle, J.; Guthrie, C.; Sanderson, S.; Birch, L.; Plomin, R., Food and activity preferences in children of lean and obese parents. Int J Obes 2001, 25, 971.

18. WHO Anthro 3.0.1, World Health Organization: Geneva, 2008.

19. IBM Corporation IBM SPSS Statistics Version 23, 2015.

20. Magarey, A.; Mauch, C. E.; Mallan, K. M.; Perry, R.; Elovaris, R.; Meedeniya, J. E.; Byrne, R.; Daniels, L. A., Child dietary and eating behavior outcomes up to 3.5 years after an early feeding intervention: The NOURISH RCT. Obesity 2016, 24 (7), 1537-1545.

21. Australian Bureau of Statistics, 4364.0.55.007 - Australian Health Survey: Nutrition First Results - Food and Nutrients, 2011-12. 2014.

22. Blissett, J.; Fogel, A., Intrinsic and extrinsic influences on children's acceptance of new foods. Phys Behav 2013, 121, 89-95.

23. National Health and Medical Research Council, Infant Feeding Guidelines. Canberra: Australian Government. 2012.

24. Caton, S. J.; Ahern, S. M.; Remy, E.; Nicklaus, S.; Blundell, P.; Hetherington, M. M., Repetition counts: repeated exposure increases intake of a novel vegetable in UK pre-school children compared to flavour-flavour and flavour-nutrient learning. Br J Nutr 2012, 109, 2089-2097.

25. Howard, A. J.; Mallan, K. M.; Byrne, R.; Magarey, A.; Daniels, L. A., Toddlers' food preferences. The impact of novel food exposure, maternal preferences and food neophobia. Appetite 2012, 59, 818-825.

26. Anzman, S. L.; Rollins, B. Y.; Birch, L. L., Parental influence on children's early eating environments and obesity risk: implications for prevention. Int J Obes 2010, 34, 1116.

27. Australian Bureau of Statistics, 4102.0 - Australian Social Trends December 2010. One for the country: recent trends in fertility. 2010.

28. Australian Institute of Health and Welfare, 2010 Australian National Infant Feeding Survey: indicator results. 2011. 